\title{
Evaluation of risk factors for a fulminant Clostridium difficile infection after cardiac surgery: a single-center, retrospective cohort study
}

Maximilian Vondran ${ }^{1,2,3^{*}+}$, Senta Schack ${ }^{1 \dagger}$, Jens Garbade ${ }^{1}$, Christian Binner ${ }^{1}$, Meinhard Mende ${ }^{4}$,

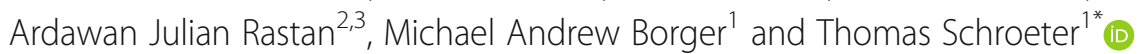

\begin{abstract}
Background: Clostridium difficile (CD) is the most common pathogen causing nosocomial diarrhea. The clinical presentation ranges from mild diarrhea to severe complications, including pseudomembranous colitis, toxic megacolon, sepsis, and multi-organ failure. When the disease takes a fulminant course, death ensues rapidly in severe and complex cases. Preventive screening or current prophylactic therapies are not useful. Therefore, this study was conducted to detect risk factors for a fulminant CD infection (CDI) in patients undergoing cardiac surgery.

Methods: Between April 1999 and April 2011, a total of 41,466 patients underwent cardiac surgery at our institution. A review of our hospital database revealed 1256 patients (3.0\%) with post-operative diarrheal disease who tested positive for CD; these patients comprised the cohort of this observational study. A fulminant CDI occurred in 153 of these patients (12.2\%), which was diagnosed on the basis of gastrointestinal complications, e.g. pseudomembranous colitis, and/or the need for post-cardiac surgery laparotomy. Demographic, peri-operative, and survival data were analyzed, and predictors of a fulminant CDI were assessed by binary logistic regression analysis.

Results: The 30-day mortality was $6.1 \%(n=77)$ for the entire cohort, with significantly higher mortality among patients with a fulminant $\mathrm{CDI}(21.6 \%$ vs. $4.0 \%, p<0.001)$. Overall mortality $(27.7 \%, n=348)$ was also higher for patients with a fulminant course of the disease $(63.4 \%$ vs. $22.8 \%, p<0.001)$, and a laparotomy was required in $36.6 \%$ $(n=56)$ of the fulminant cases. Independent predictors of a fulminant CDI were: diabetes mellitus type 2 (OR 1.74, $\mathrm{Cl} 1.15-2.63, p=0.008$ ), pre-operative ventilation (OR 3.52, Cl 1.32-9.35, $p=0.012$ ), utilization of more than 8 units of red blood cell concentrates (OR 1.95, Cl 1.01-3.76, $p=0.046)$ or of more than 5 fresh-frozen plasma units (OR $3.38, \mathrm{Cl}$ $2.06-5.54, p<0.001$ ), and a cross-clamp time $>130$ min (OR 1.93, Cl 1.12-3.33, $p=0.017$ ).

Conclusions: We identified several independent risk factors for the development of a fulminant CDI after cardiac surgery. Close monitoring of high-risk patients is important in order to establish an early onset of therapy and thus to prevent a CDI from developing a fulminant course after cardiac surgery.
\end{abstract}

Keywords: Intensive care, Clostridium difficile, Cardiac surgery, High risk, Critical care

\footnotetext{
* Correspondence: m.vondran@hkz-rotenburg.de; thomas.schroeter@heliosgesundheit.de

Presented at the 2018 Annual Meeting of the German Society of Cardiothoracic Surgery in Leipzig, February 17-20th.

${ }^{+}$Maximilian Vondran and Senta Schack contributed equally to this work.

${ }^{1}$ University Department for Cardiac Surgery, Heart Center Leipzig,

Struempellstr. 39, 04289 Leipzig, Germany

Full list of author information is available at the end of the article
}

(c) The Author(s). 2018 Open Access This article is distributed under the terms of the Creative Commons Attribution 4.0 International License (http://creativecommons.org/licenses/by/4.0/), which permits unrestricted use, distribution, and reproduction in any medium, provided you give appropriate credit to the original author(s) and the source, provide a link to the Creative Commons license, and indicate if changes were made. The Creative Commons Public Domain Dedication waiver (http://creativecommons.org/publicdomain/zero/1.0/) applies to the data made available in this article, unless otherwise stated. 


\section{Background}

In recent years, the bacterium Clostridium difficile (CD), a gram-positive, spore-forming, anaerobic bacilli that has been known for almost a century, has played an increasingly important role in postoperative infections. There is currently a growing incidence of diarrhea caused by CD, and especially after the administration of antibiotics about $10 \%$ to $20 \%$ of all diarrheal cases can be attributed to CD [1]. Subclinical colonization with CD is not at all uncommon; for example, it is estimated that up to $80 \%$ of children may be affected [2]. This pathogen is the most common cause of nosocomial diarrhea $[3,4]$. The incidence of CDassociated diarrhea after various surgical procedures varies from 0.3 to $8.4 \%$ [5] in the current literature, depending on the surgical cohort investigated, and mild to moderate severity of CD-associated diarrhea translates into a longer hospital stay. A fulminant course, however, with pseudomembranous colitis and severe complications such as toxic megacolon, including intestinal perforation with sepsis and multi-organ failure, significantly increases mortality after surgical procedures [6]. Despite knowledge gained about $\mathrm{CD}$ as one of the most important nosocomial pathogens and extensive investigation of its influence on patients in nursing homes, little is known about the incidence and risk factors for the development of a CD infection (CDI) after surgical interventions, especially in cardiac surgery.

Closer inspection reveals that cardiac surgical patients in particular suffer from many of the prerequisites for colonization with $\mathrm{CD}$ with regard to the known predisposition factors, including antibiotic prophylaxis, age, diabetes mellitus, renal or cardiac insufficiency, use of blood products, duration of extracorporeal circulation and ischemic period, and length of stay on an intensive care unit (ICU) [5, 7-10].

There are a few reports available that address CDI and clinical outcomes following cardiac surgery [5, 8-10]. However, there is no study to date that focuses on CDI with a fulminant course. The purpose of this single-center, retrospective study was to identify risk factors for the development of a fulminant CDI after cardiac surgery. Additional attention was given to the clarification of the incidence and mortality of bland and fulminant CDI and the clinical outcomes of the patients during follow-up.

\section{Methods}

\section{Patients}

Between April 1999 and April 2011, 41,466 patients underwent cardiac surgery at our center. Demographics and pre-, intra-, and post-operative data were collected prospectively for all patients in a digital hospital registry. A review of this registry revealed that 1256 out of 41,466 (3.0\%) patients were diagnosed with a CDI during their hospital stay. The presence of a CDI was verified using medical records, discharge summaries from other institutions, and documentation of findings from other departments. The local ethics committee approved the study (University of Leipzig, Az.: 212-15-01062015). The study design, anonymous data acquisition, and the publication of the data were in accordance with the Declaration of Helsinki.

\section{Diagnosis of CDI}

CDI was diagnosed by a combination of clinical symptoms and laboratory testing. The criteria for a CDI were frequent stool ( $>3$ times/day) with unformed consistency (water content of the stool $>75 \%$ ), increased stool masses (> $250 \mathrm{~g} /$ day), and stool testing positive for CD [11]. The stool examination was made with cytotoxicity assay and/ or enzyme immunoassay for CD toxins. All patients who fulfilled these criteria were included in this retrospective cohort study $(n=1256)$. Patients were excluded if they met any of the following criteria: age $<18$ years, a hospital stay of less than $48 \mathrm{~h}$, and positive test for CD at the time of hospital admission. The occurrence of gastrointestinal complications (e.g. pseudomembranous colitis, toxic megacolon, gastrointestinal bleeding, ileus, ischemia, or perforation, etc.) and/or the need for a laparotomy after cardiac surgery were defined as criteria for a fulminant CDI (Table 1).

\section{Statistics}

Unless otherwise indicated, categorical variables are presented as numbers and percentage, and continuous parameters are expressed as mean \pm standard deviation (SD). Fisher's exact test or a Chi-squared test was used to assess differences for categorical variables, and Student's t-test or a Wilcoxon rank-sum test was applied for continuous parameters. Overall survival rates were analyzed using the Kaplan-Meier method. Statistical differences were calculated by the log-rank test. Multivariate analysis was performed using a binary logistic regression model (stepwise backward) to differentiate independent risk factors for developing a fulminant course of CDI. Variables used in the equation were prior cardiac surgery, pre-operative dialysis, pre-operative ventilation, pre-operative low cardiac

Table 1 Gastrointestinal complications

\begin{tabular}{lll}
\hline Variable & \multicolumn{2}{l}{ CDI positive $n=1256$} \\
\cline { 2 - 3 } & $\mathrm{n}$ & $\%$ \\
\hline Laparotomy & 56 & 4.5 \\
Gastrointestinal bleeding & 54 & 4.3 \\
Acute abdomen and/or peritonitis & 20 & 1.6 \\
and/or perforation & & 1.8 \\
lleus/ischemia & 23 & 2.8 \\
Pseudomembranous colitis & 35 & 0.6 \\
Toxic megacolon & 7 & 1.6 \\
Other abdominal complications & 20 &
\end{tabular}

Abbreviations: $C D$ I Clostridium difficile infection 
output, emergency surgery, minimally invasive surgery, diabetes mellitus type 2 , age $>80$ years, left ventricular ejection fraction (LVEF) $<30 \%$, New York Heart Association (NYHA) class $\geq$ III, length of surgery $>200 \mathrm{~min}$, cross-clamp time $>130$ min, $>8$ units of red blood cell (RBC) concentrates, $>5$ units of fresh-frozen plasma (FFP).

All tests were two-sided, with a significance level alpha $=0.05$. Unless otherwise stated the analyses were performed by IBM SPSS Statistics for Macintosh, Version 24.0 (IBM Corp., Armonk, NY, USA). All authors had full access to datasets and upheld their integrity. They read and agreed to the manuscript as written.

\section{Results}

Table 2 summarizes all pre-operative patient characteristics. A total of 1256 patients (3.0\% of cardiac surgery patients) developed a post-operative CDI between April 1999 and April 2011. Of these, 153 (12.2\%) developed a fulminant CDI during their stay. The patients with a fulminant CDI had a significantly lower pre-operative LVEF than that of the group with a bland CDI. Furthermore, the pre-operative proportion of patients with diabetes mellitus, LVEF $<30 \%$, age $>80$ years, prior cardiac surgery, ventilator dependence, and a poor NYHA functional class was significantly higher for the group developing a fulminant CDI.

Table 3 summarizes all peri-procedural details. The duration of surgery, cardiopulmonary bypass $(\mathrm{CPB})$ time, cross-clamp time, and time of reperfusion were significantly longer for the patients with a fulminant CDI. The percentage of patients needing emergency surgery was also significantly higher in the group with a fulminant $\mathrm{CDI}$, whereas minimally invasive surgery was performed significantly more often in the group with bland CDI.

Table 4 summarizes post-operative outcomes. The post-operative course of the patients with a fulminant CDI was associated with more complications. This group required mechanical circulatory assist devices (MCAD) significantly more often. Whereas the bland CDI group needed MCAD in just 4.6\% $(n=51)$ of cases, MCAD was required in $19.0 \%(n=51)$ of patients with a fulminant course. The proportion of intra-aortic balloon pump (IABP) support as MCAD was $93.1 \%$ in the fulminant CDI group and $80.4 \%$ in the bland CDI group. $(p=0.221)$. Moreover, renal replacement therapy, re-intubation, and a tracheostomy was required significantly more often in the group with fulminant CDI. Furthermore, post-operative neurological dysfunction was diagnosed more frequently in the patients with a fulminant CDI. The utilization of RBC concentrates, FFP units, and platelet concentrates was significantly greater for the patients with a fulminant CDI, and these patients were ventilated longer and the length of ICU or intermediate care unit stay was significantly longer.
The 30-day all-cause mortality was $6.1 \%(n=77)$ and overall all-cause mortality was $27.7 \%(n=348)$ for the entire study cohort. Patients with a fulminant CDI had a significantly higher 30-day all-cause mortality rate than patients with a bland CDI $(21.6 \%$ vs. $4.0 \%, p<0.001)$. Moreover, the overall all-cause mortality was significantly higher for patients with a fulminant CDI (63.4\% vs. $22.8 \%$, $p<0.001$; Fig. 1). The median follow-up time was 8 (interquartile range: 2 ; 30 ) months. Diabetes mellitus type 2 , pre-operative ventilation, utilization of more than $8 \mathrm{RBC}$ concentrates, more than 5 FFP units, and a cross-clamp time $>130$ min were multiple independent predictors of a fulminant CDI (Table 5).

\section{Discussion}

Post-operative diarrhea is a common, underestimated complication after surgery that can be caused by $\mathrm{CD}$. While the majority of CDI cases are harmless, in $8-16 \%$ a fulminant CDI with severe complications occurs [12-14] that significantly increases mortality after surgical procedures [6]. Little data exists on the incidence and risk factors for the development of a CDI after cardiac surgery, especially for fulminant CDI. The present study is the first to address fulminant CDI after cardiac surgery. The findings of this study can be summarized as follows: $12.2 \%$ of the CDI cases in our cohort were fulminant; fulminant CDI increases 30-day and overall all-cause mortality significantly compared with bland CDI; independent risk factors for a fulminant CDI are pre-operative diabetes mellitus type 2 , pre-operative ventilation, cross-clamp time $>130 \mathrm{~min}$, the utilization of more than 8 RBC units or more than 5 FFP units.

\section{Incidence}

The incidence of post-operative CDI varies in the current literature and often depends on the surgery performed, decade of the study, and the study design. It ranges from 0.3 to $8.4 \%$ [5]. The most recent data from studies of cardiac surgery dealing with the topic of post-surgical CDI show very low incidences, ranging between $0.3-0.79 \%$, with a tremendous increase worldwide a few years after the beginning of the new millennium $[5,8,9]$. Our cohort seems to reflect more the data of a real-world cohort, with an overall incidence of 3.0\%. However, Crabtree et al. reported that in June 2003 their highest incidence was $8.89 \%$ [5]. Since 2003, not only an increase in the incidence of CDI but also the severity of the disease has been reported worldwide [15]. In Germany, an analysis of the discharge diagnoses of the years 2000-2004 showed a clear increase in CDI from 7 to 39 cases per 100,000 inpatients; between 2004 and 2006 it doubled again [16, 17]. In the context of clusters that first appeared in North America and then in Europe, including Germany, a new epidemic strain with particular virulence has been reported $[15,18]$. 
Table 2 Patient characteristics

\begin{tabular}{|c|c|c|c|c|c|c|c|}
\hline \multirow[t]{2}{*}{ Variable } & \multicolumn{2}{|c|}{ All CDI patients $n=1256$} & \multicolumn{2}{|c|}{ Bland CDI $n=1103$} & \multicolumn{2}{|c|}{ Fulminant CDI $n=153$} & \multirow[t]{2}{*}{$p$-Value } \\
\hline & Mean & SD & Mean & SD & Mean & SD & \\
\hline Age, y & 72.2 & 10.5 & 72.3 & 10.6 & 71.6 & 10.1 & 0.444 \\
\hline Left ventricular ejection fraction, \%, & 53.9 & 14.5 & 54.4 & 14.3 & 51.0 & 15.8 & 0.013 \\
\hline \multirow[t]{2}{*}{ Creatinine, mg/dl } & 1.22 & 1.03 & 1.21 & 1.02 & 1.27 & 1.08 & 0.484 \\
\hline & $n$ & $\%$ & $n$ & $\%$ & $\mathrm{n}$ & $\%$ & \\
\hline Male & 732 & 58.3 & 631 & 57.2 & 101 & 66.0 & 0.440 \\
\hline Age $>80$ years & 246 & 19.6 & 227 & 20.6 & 19 & 12.8 & 0.027 \\
\hline LVEF $<30 \%$ & 112 & 8.9 & 90 & 8.2 & 22 & 14.4 & 0.015 \\
\hline Diabetes mellitus & 468 & 37.3 & 396 & 35.9 & 72 & 47.1 & 0.009 \\
\hline Coronary heart disease & 675 & 53.7 & 596 & 54.0 & 79 & 51.6 & 0.858 \\
\hline Prior acute myocardial infarction & 313 & 24.9 & 272 & 24.7 & 41 & 26.8 & 0.551 \\
\hline Peripheral artery disease & 355 & 28.3 & 319 & 28.9 & 36 & 23.5 & 0.180 \\
\hline Pre-operative dialysis & 66 & 5.3 & 53 & 4.8 & 13 & 8.5 & 0.078 \\
\hline Hypertension & 1053 & 83.8 & 930 & 84.3 & 123 & 80.4 & 0.241 \\
\hline PAP $\geq 60 \mathrm{mmHG}$ & 101 & 8.0 & 87 & 7.9 & 14 & 9.2 & 0.633 \\
\hline Chronic obstructive pulmonary disease & 127 & 10.1 & 108 & 9.8 & 19 & 12.4 & 0.317 \\
\hline Hyperlipidemia & 657 & 52.2 & 581 & 52.7 & 75 & 49 & 0.437 \\
\hline Nicotine abuse & 352 & 28.0 & 317 & 28.7 & 35 & 22.9 & 0.150 \\
\hline Prior cardiac surgery & 161 & 12.8 & 128 & 11.6 & 33 & 21.6 & 0.001 \\
\hline Prior malignant disease & 78 & 6.2 & 69 & 6.3 & 9 & 5.9 & 1.000 \\
\hline Pre-operative neurological dysfunction & 107 & 8.5 & 92 & 8.3 & 15 & 9.8 & 0.537 \\
\hline Pre-operative ventilation & 21 & 1.7 & 12 & 1.1 & 9 & 5.9 & $<0.001$ \\
\hline Pre-operative any mechanical circulatory assist device & 32 & 2.5 & 26 & 2.4 & 6 & 4.0 & 0.477 \\
\hline \multicolumn{8}{|l|}{ NYHA class } \\
\hline । & 93 & 7.4 & 88 & 8.0 & 5 & 3.3 & \\
\hline$\|$ & 330 & 26.3 & 297 & 26.9 & 33 & 21.6 & \\
\hline III & 644 & 51.3 & 559 & 50.7 & 85 & 55.6 & \\
\hline IV & 189 & 15.0 & 159 & 14.4 & 30 & 19.6 & 0.036 \\
\hline$\geq\|I\|$ & 189 & 15.0 & 159 & 14.4 & 30 & 19.6 & 0.116 \\
\hline Body mass index $\geq 25.0 \mathrm{~g} / \mathrm{m}^{2}$ & 830 & 66.1 & 725 & 65.8 & 105 & 68.6 & 0.478 \\
\hline
\end{tabular}

Abbreviations: $C D /$ Clostridium difficile infection

\section{Mortality}

Current data on 30-day mortality in patients with CDI vary between 2.5 and $26 \%$ [8, 9, 19, 20], depending on the study population. Thus, a 30 -day mortality rate of $26 \%$ reported by Musa et al. was based on a collective of only 27 ICU patients after cardiothoracic surgery [20]. Keshavamurthy and colleagues published an in-hospital mortality rate of $11 \%$ in 2014 for a cohort of 145 patients who underwent cardiac surgery at the Cleveland Clinic [9]. Flagg et al. analyzed 349,122 patients after cardiac surgery from 2004 to 2008 from the Nationwide Inpatient Sample database. The in-hospital mortality of their cohort of CDI patients was $12 \%$ [8]. Both studies reported a significantly higher 30-day mortality for patients with CDI after cardiac surgery, whereas Crabtree et al. found similar survival rates between different surgical groups [5]. Lemaire et al. showed in their study that with a post-operative CDI, the risk of in-hospital mortality nearly doubles [10]. In the present study, a 30-day mortality of $4.0 \%$ was observed for the group with bland CDI and $21.6 \%$ for the group with fulminant disease. At this point, it should be emphasized how clearly the 30-day mortality of the patients with fulminant disease is increased compared with those with bland CDI. With more than $20 \%$ mortality in the first 30 days, a fulminant CDI must be viewed as a highly life-threatening condition.

Reports of overall or long-term mortality following a CDI have yielded various results. A retrospective study by Morrison et al. reported an overall mortality rate of $5 \%$, whereas Keshavamurthy found a 3-year mortality in their CDI cohort as high as $48 \%[9,21]$. Crabtree et al. 
Table 3 Procedural details

\begin{tabular}{|c|c|c|c|c|c|c|c|}
\hline \multirow[t]{2}{*}{ Variable } & \multicolumn{2}{|c|}{ All CDI patients $n=1256$} & \multicolumn{2}{|c|}{ Bland CDI $n=1103$} & \multicolumn{2}{|c|}{ Fulminant CDI $n=153$} & \multirow[t]{2}{*}{$p$-Value } \\
\hline & Mean & SD & Mean & SD & Mean & SD & \\
\hline Length of surgery, min & 194.8 & 91.6 & 191.3 & 89.4 & 220.7 & 103.3 & $<0.001$ \\
\hline CPB time, min & 127.6 & 55.7 & 124.8 & 53.1 & 146.0 & 67.8 & 0.001 \\
\hline Cross-clamp time, min & 82.9 & 34.7 & 81.3 & 33.5 & 94.4 & 40.5 & $<0.001$ \\
\hline Time of reperfusion, min & 31.7 & 24.3 & 30.8 & 22.9 & 38.3 & 32.0 & 0.020 \\
\hline \multirow[t]{2}{*}{ Time of circulatory arrest, min } & 34.3 & 22.5 & 33.8 & 23.9 & 36.1 & 17.3 & 0.808 \\
\hline & $\mathrm{n}$ & $\%$ & $\mathrm{n}$ & $\%$ & $\mathrm{n}$ & $\%$ & \\
\hline Emergency surgery & 144 & 11.5 & 113 & 10.2 & 31 & 20.3 & 0.001 \\
\hline Length of surgery $>200$ min & 546 & 43.5 & 465 & 42.2 & 81 & 52.9 & 0.015 \\
\hline Cross-clamp time $>130 \mathrm{~min}$ & 503 & 40.1 & 420 & 38.0 & 83 & 54.0 & 0.001 \\
\hline \multicolumn{8}{|l|}{ Surgery performed } \\
\hline Valve & 550 & 43.8 & 485 & 44.0 & 65 & 42.5 & 0.728 \\
\hline CABG & 244 & 19.4 & 212 & 19.2 & 32 & 20.9 & 0.619 \\
\hline Aortic & 31 & 2.5 & 26 & 2.4 & 5 & 3.3 & 0.496 \\
\hline Others or combination & 431 & 34.4 & 380 & 34.5 & 51 & 33.3 & 0.785 \\
\hline Any ablation for AF & 170 & 13.5 & 152 & 13.8 & 18 & 11.8 & 0.614 \\
\hline Intra-operative any mechanical circulatory assist device & 67 & 5.3 & 52 & 4.7 & 15 & 9.8 & 0.070 \\
\hline Minimally invasive surgery & 424 & 33.8 & 389 & 35.3 & 35 & 22.9 & 0.009 \\
\hline CPB & 950 & 75.6 & 826 & 74.9 & 124 & 81.0 & 0.071 \\
\hline Circulatory arrest & 34 & 2.7 & 27 & 2.4 & 4 & 4.6 & 0.129 \\
\hline
\end{tabular}

Abbreviations: AF Atrial fibrillation, $C A B G$ Coronary artery bypass grafting, $C D I$ Clostridium difficile infection, $C P B$ Cardiopulmonary bypass

Table 4 Postoperative Outcomes

\begin{tabular}{|c|c|c|c|c|c|c|c|}
\hline \multirow[t]{2}{*}{ Variable } & \multicolumn{2}{|c|}{ CD positive $n=1256$} & \multicolumn{2}{|c|}{ Bland CDI $n=1103$} & \multicolumn{2}{|c|}{ Fulminant CDI $n=153$} & \multirow[t]{2}{*}{$p$-Value } \\
\hline & Mean & SD & Mean & SD & Mean & SD & \\
\hline RBC, units & 8.0 & 14.1 & 6.44 & 11.9 & 19.2 & 21.6 & $<0.001$ \\
\hline FFP, units & 5.3 & 13.2 & 3.8 & 10.0 & 16.3 & 24.2 & $<0.001$ \\
\hline Platelets, units & 1.2 & 3.8 & 0.9 & 3.4 & 3.4 & 5.6 & $<0.001$ \\
\hline Ventilation time up to first extubation, $\mathrm{h}$ & 81.6 & 225.3 & 66.3 & 187.1 & 187.0 & 383.8 & $<0.001$ \\
\hline Total ventilation time, $\mathrm{h}$ & 181.4 & 359.7 & 1384 & 289.8 & 477.6 & 585.6 & $<0.001$ \\
\hline Total LOS ICU, h & 282.3 & 430.9 & 234.7 & 364.5 & 586.9 & 647.4 & $<0.001$ \\
\hline \multirow[t]{2}{*}{ Total LOS IMCU, h } & 202.8 & 380.5 & 188.5 & 372.5 & 319.6 & 424.6 & 0.002 \\
\hline & $\mathrm{n}$ & $\%$ & $\mathrm{n}$ & $\%$ & $\mathrm{n}$ & $\%$ & \\
\hline Post-operative any mechanical circulatory assist device & 80 & 6.4 & 51 & 4.6 & 29 & 19.0 & $<0.001$ \\
\hline Post-operative dialysis & 301 & 24.0 & 221 & 20.0 & 80 & 52.3 & $<0.001$ \\
\hline Re-intubation & 370 & 29.5 & 286 & 25.9 & 84 & 54.9 & $<0.001$ \\
\hline Tracheostomy & 197 & 15.7 & 135 & 12.2 & 62 & 40.5 & $<0.001$ \\
\hline Re-thoracotomy & 169 & 13.5 & 146 & 13.2 & 23 & 15.0 & $<0.001$ \\
\hline Post-operative neurological dysfunction & 948 & 75.5 & 817 & 74.1 & 131 & 85.6 & 0.002 \\
\hline$>8$ units $\mathrm{RBC}$ & 750 & 59.7 & 616 & 55.8 & 134 & 87.6 & $<0.001$ \\
\hline$>5$ units FFP & 477 & 38.0 & 366 & 33.2 & 111 & 72.5 & $<0.001$ \\
\hline$>2$ units platelets & 144 & 11.5 & 98 & 8.9 & 46 & 30.1 & $<0.001$ \\
\hline
\end{tabular}

Abbreviations: FFP Fresh-frozen plasma, ICU Intensive care unit, IMCU Intermediate care unit, LOS Length of surgery, RBC Red blood cells 


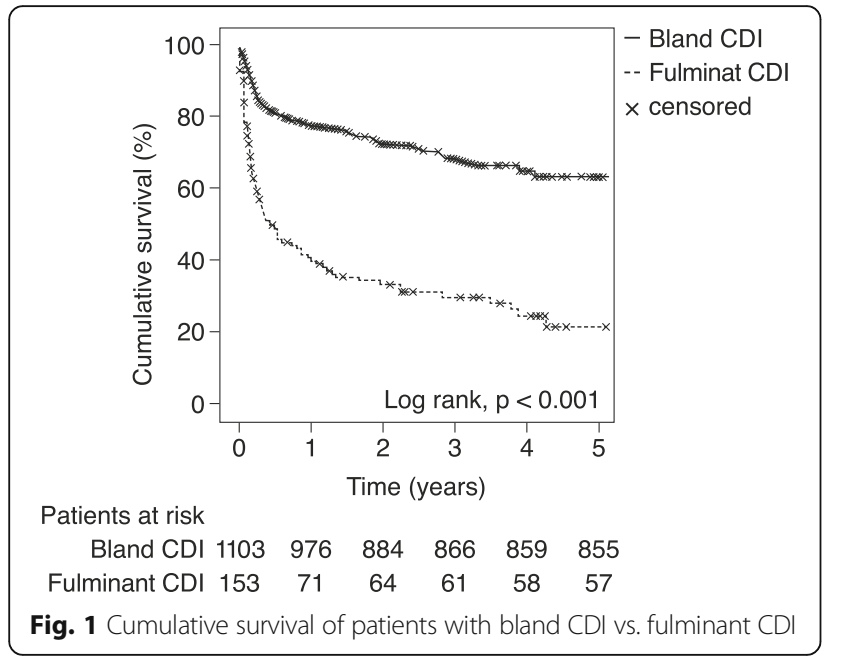

described an overall mortality of $6 \%$ for a cohort of post-operative CDI patients, although the overall mortality rate for the subgroup with fulminant CDI was 30\% [5]. Further studies reported mortality rates for the group of patients with fulminant CDI of up to $50 \%$ and up to $80 \%$ in cases requiring emergency colectomy [21, 22]. In the present study we observed an overall mortality in the collective with bland CDI of $22.8 \%$. In contrast, in the group with a fulminant course, the overall mortality was $63.4 \%$. Moreover, most of the deaths occurred in the first 3 months after cardiac surgery, whether the CDI was fulminant or bland.

\section{Risk factors for the development of a fulminant CDI}

Cardiopulmonary comorbidities have been repeatedly documented in the literature as risk factors for the development of fulminant CDI $[23,24]$. The present work underpins these observations. Reduced LVEF and elevated NYHA functional class are dependent risk factors and pre-operative mechanical ventilation is an independent risk factor for the development of a fulminant CDI. Likewise, prior cardiac surgery in the present study was a dependent risk factor for the development of a fulminant CDI. Thus, both idiopathic and iatrogenic cardiopulmonary factors create a vulnerable niche for severe CDI [25].

Table 5 Results of the logistic regression analysis

\begin{tabular}{lllll}
\hline Variable & Odds Ratio & $95 \% \mathrm{Cl}$ & & $p$-Value \\
\hline Diabetes mellitus & 1.743 & 1.154 & 2.633 & 0.008 \\
Pre-operative ventilation & 3.517 & 1.323 & 9.353 & 0.012 \\
Cross-clamp time > 130 min & 1.934 & 1.123 & 3.329 & 0.017 \\
$>8$ units RBC & 1.952 & 1.012 & 3.764 & 0.046 \\
$>5$ units FFP & 3.382 & 2.063 & 5.544 & $<0.001$ \\
\hline
\end{tabular}

Abbreviations: Cl Confidence interval, FFP Fresh-frozen plasma, RBC Red blood cells
Also worthy of mention is the relationship between severe disease progression and the indication for surgery. Patients admitted for emergency procedures showed significantly more fulminant events than patients undergoing elective surgery. This concurs with the previously published studies and suggests that the toxicity of the pathogen in already pre-operatively weakened patients with a higher rate of circulatory instability results in far graver outcomes than in elective patients with a lower peri-operative stress response [10].

As mentioned above, pre-operative mechanical ventilation is a further independent risk factor for the development of a fulminant CDI. In general, a patient who has been ventilated before cardiac surgery is rarely in good clinical condition. Here, the body is exposed to a high degree of stress even before the surgical procedure. Furthermore, ventilation itself can contribute additional immunosuppression [26], which may support a fulminant CDI.

The peri-operative administration of blood products has been frequently associated in the literature with an aggravation of the course of the disease and with modulation of recipients' immune function [5, 20, 27]. The present work underlines these observations: peri-operative administration of more than eight RBC units or five FFP units increased the risk of a fulminant course by two to three times. A controversial issue here is whether the administration of blood products is a true, aggravating factor or rather a harbinger of the increasing severity of the disease.

The available data on the influence of peri-operative MCAD on the incidence and severity of CDI is very scarce [20], but the use of these devices seems to have an effect on outcome [28]. The present study shows an influence of the post-operative use of a MCAD on the course of a CDI. In the vast majority of our cases, this was the implantation of an IABP in hemodynamically unstable patients. The risk of developing a fulminant CDI was increased in patients who were treated with a MCAD. Importantly, a previous study has shown that up to $97 \%$ of implanted IABP devices may compromise the blood flow of the visceral arteries by overlapping them [29]. About 25\% of cases become clinically symptomatic, show intestinal ischemia, and/or have to be treated by laparotomy. In addition to the existing infection and hemodynamic instability, the gastrointestinal tract is especially vulnerable due to compression of visceral arteries by the IABP and consequently reduced perfusion [30]. This is a possible explanation for the significantly increased rate of gastrointestinal complications and visceral surgical interventions in the collective of patients treated with a MCAD.

The duration of surgery and $\mathrm{CPB}$ were found to be dependent risk factors, and the cross-clamp time was an independent risk factor for the development of fulminant CDI. Crabtree et al. were also able to demonstrate the influence of prolonged surgical duration with prolonged $\mathrm{CPB}$ time on the development of $\mathrm{CDI}$ and protraction of 
underlying disease [5]. The present study also shows that in patients who underwent surgery through a minimally invasive approach, the risk of developing fulminant versus bland CDI was reduced. Thus, minimally invasive surgery was a univariate protective predictor against a fulminant CDI. The clear advantage of minimally invasive surgery is the less traumatic procedure due to smaller wounds and less peri-operative blood loss as well as shorter length of stay on the ICU or intermediate care unit. The present study demonstrated that the length of stay in intensive and intermediate care were dependent risk factors for developing a fulminant $\mathrm{CDI}$, which was also described in previous investigations $[5,20,31]$. These results should be interpreted with caution, however, as causality of the relationships may be open to discussion. Therefore, the statistical categorization between cause and effect of the phenomenon regarding the $\mathrm{CDI}$ and the ICU/intermediate care unit stay is difficult. In summary, a prolonged hospital stay is most likely both a risk factor for the development of a fulminant CDI and a consequence of it.

\section{Limitations}

In the present work, no ribotyping of the CD strains was performed; therefore, possible influences of hypervirulent strains could not be independently evaluated. Due to the retrospective study design, it was no longer possible to determine leukocyte counts, lactate values, and creatinine levels of the patients at the time of infection. However, these parameters were frequently used in the literature to classify the severity of CDI [32]. In this work, only the development of gastrointestinal complications and the need for laparotomy could be used; thus, such a classification was not possible. The content of an RBC, FFP and platelet concentrate unit varies and was not individually recorded in our work, as only the administered units have been documented. The volume of one unit was appx. $250 \mathrm{ml}$. Furthermore, we did not have sufficient information about the other hospitals or nursing homes from which the patients were transferred who were admitted to the Heart Center Leipzig. The retrospective study design also prohibited us from clearly reconstructing in all patients whether antibiotics had already been administered pre-operatively or not. It is well known that antibiotics cause CDI, but they are also components of optimal therapy of fulminant CDI. Because of this and the unstable data, we did not include antibiotic therapy as such in our risk stratification model. Finally, the relapse rate was not determined in the present study. There are indications in the literature that more than one third of CDI patients experience at least one relapse [14].

\section{Conclusions}

In the present study we were able to detect independent risk factors for the development of a fulminant CDI. It is striking that the multivariate predictors would all appear to have a negative effect on the immune system or in some way to lower immune system defenses via stress on the patient's body. The severity of the course of CDI, in our view, depends on the vulnerability of the immune system and the stimuli that compromise it. A disturbance of the intestinal physiology and thus the microbial intestinal flora, e.g. by gastrointestinal diseases, surgical interventions, or antibiotic treatment, plays the biggest role here. Since preventive screening or prophylactic therapies are not useful, high-risk patients can be selected and targeted for close monitoring and an early intervention to avoid a fulminant course of an infection. By providing knowledge about peri-operative risk factors, this work can be a step towards the establishment of consistent risk stratification systems. Until new and effective treatment concepts are established, the selection of particularly vulnerable patients and their targeted observation is a way to control fulminant CDI of nosocomial origin.

\section{Abbreviations \\ AF: Atrial fibrillation; CABG: Coronary artery bypass grafting; CD: Clostridium difficile; CDI: Clostridium difficile infection; CPB: Cardiopulmonary bypass; FFP: Fresh-frozen plasma; IABP: Intra-aortic balloon pump; ICU: Intensive care unit; IMCU: Intermediate care unit; LOS: Length of surgery; \\ LVEF: Left ventricular ejection fraction; MCAD: Mechanical circulatory assist devices; NYHA: New York Heart Association; RBC: Red blood cells; SD: Standard deviation}

\section{Acknowledgements}

The authors wish to thank Peter Meyer (Bureau M/M, Stuttgart-Leipzig, Germany) for preparing the figures.

\section{Availability of data and materials}

The datasets used and/or analysed during the current study are available from the corresponding author on reasonable request.

\section{Authors' contributions}

Concept/design: JG, CB, TS; Data analysis/interpretation: MV, SS, MM, CB, TS; Drafting article: MV; Critical revision of article: MV, MI, AJR, MAB, TS; Approval of article: MV, SS, JG, MM, CB, MI, AJR, MAB, TS; Statistics: MV, SS, JG, MM, CB, TS; Funding secured by: -; Data collection: SS, CB, TS. All authors read and approved the final manuscript.

\section{Ethics approval and consent to participate}

The local ethics committee approved the study (University of Leipzig, Az. 212-15-01062015). The study design, anonymous data acquisition, and the publication of the data were in accordance with the Declaration of Helsinki.

\section{Consent for publication}

Not applicable

\section{Competing interests}

The authors declare that they have no competing interests.

\section{Publisher's Note}

Springer Nature remains neutral with regard to jurisdictional claims in published maps and institutional affiliations.

\section{Author details}

'University Department for Cardiac Surgery, Heart Center Leipzig,

Struempellstr. 39, 04289 Leipzig, Germany. ${ }^{2}$ Department of Cardiovascular Surgery, Thoracic and Vascular Surgery, University Hospital Marburg (UKGM), Baldingerstr, 35043 Marburg, Germany. ㄹ Department of Cardiac Surgery, 
Center of Cardiovascular Diseases Rotenburg a. d. Fulda, Heinz-Meise-Str. 100, 36199 Rotenburg a. d. F, Germany. ${ }^{4}$ Center for Clinical Trials, University of Leipzig, Härtelstraße 16/18, 04107 Leipzig, Germany.

Received: 3 July 2018 Accepted: 17 September 2018

Published online: 27 September 2018

\section{References}

1. Gerding DN. Disease associated with Clostridium difficile infection. Ann Intern Med. 1989;110:255-7.

2. Bartlett JG. Narrative review: the new epidemic of Clostridium difficileassociated enteric disease. Ann Intern Med. 2006;145:758-64.

3. Barbut F, Leluan P, Antoniotti G, Collignon A, Sedallian A, Petit J. Value of routine stool cultures in hospitalized patients with diarrhea. Eur J Clin Microbiol Infect Dis. 1995;14:346-9.

4. Rohner P, Pittet D, Pepey B, Nije-Kinge T, Auckenthaler R. Etiological agents of infectious diarrhea: implications for requests for microbial culture. J Clin Microbiol. 1997:35:1427-32.

5. Crabtree T, Aitchison D, Meyers BF, Tymkew H, Smith JR, Guthrie TJ, et al. Clostridium difficile in cardiac surgery: risk factors and impact on postoperative outcome. Ann Thorac Surg. 2007;83:1396-402.

6. Lesperance K, Causey MW, Spencer M, Steele SR. The morbidity of Clostridium difficile infection after elective colonic resection-results from a national population database. Am J Surg. 2011:201:141-8.

7. Munoz P, Giannella M, Alcala L, Sarmiento E, Fernandez Yanez J, Palomo J, et al. Clostridium difficile-associated diarrhea in heart transplant recipients: is hypogammaglobulinemia the answer? J Heart Lung Transplant. 2007;26: 907-14

8. Flagg A, Koch CG, Schiltz N, Chandran Pillai A, Gordon SM, Pettersson GB, et al. Analysis of Clostridium difficile infections after cardiac surgery: epidemiologic and economic implications from national data. J Thorac Cardiovasc Surg. 2014;148:2404-9.

9. Keshavamurthy S, Koch CG, Fraser TG, Gordon SM, Houghtaling PL, Soltesz EG, et al. Clostridium difficile infection after cardiac surgery: prevalence, morbidity, mortality, and resource utilization. J Thorac Cardiovasc Surg. 2014;148:3157-65 e1-5.

10. Lemaire A, Dombrovskiy V, Batsides G, Scholz P, Solina A, Brownstone N et al. The effect of Clostridium difficile infection on cardiac surgery outcomes. Surg Infect. 2015:16:24-8.

11. Herold G. Innere Medizin : eine vorlesungsorientierte Darstellung : 2017 : unter Berücksichtigung des Gegenstandskataloges für die Ärztliche Prüfung : mit ICD 10-Schlüssel im Text und Stichwortverzeichnis. Köln: Gerd Herold, 2017.

12. Adams SD, Mercer DW. Fulminant Clostridium difficile colitis. Curr Opin Crit Care. 2007:13:450-5

13. Boutros M, Al-Shaibi M, Chan G, Cantarovich M, Rahme E, Paraskevas S, et al. Clostridium difficile colitis: increasing incidence, risk factors, and outcomes in solid organ transplant recipients. Transplantation. 2012;93:1051-7.

14. Dubberke ER, Riddle DJ, Practice ASTIDCo. Clostridium difficile in solid organ transplant recipients. Am J Transplant 2009;9 Suppl 4:S35-S40.

15. Kuijper EJ, Coignard B, Tull P, difficile ESGfC, States EUM, European Centre for Disease $\mathrm{P}$, et al. Emergence of Clostridium difficile-associated disease in North America and Europe. Clin Microbiol Infect. 2006;12(Suppl 6):2-18.

16. Vonberg R, Gastmeier P. Clostridium-difficile-assoziierte Diarrhö: Zunehmende Inzidenz in Deutschland. Epidemiol Bull. 2008;119.

17. Vonberg R-P, Schwab F, Gastmeier P. Clostridium difficile in discharged inpatients. Germany Emerging infectious diseases. 2007:13:179.

18. Kleinkauf N, Weiss B, Jansen A, Eckmanns T, Bornhofen B, Kuehnen E, et al. Confirmed cases and report of clusters of severe infections due to Clostridium difficile PCR ribotype 027 in Germany. Euro Surveill. 2007;12:E071115.

19. Kyne L, Hamel MB, Polavaram R, Kelly CP. Health care costs and mortality associated with nosocomial diarrhea due to Clostridium difficile. Clin Infect Dis. 2002;34:346-53.

20. Musa SA, Moran C, Thomson SJ, Cowan ML, MCAnulty G, Grounds M, et al. Clostridium difficile-associated disease acquired in the cardiothoracic intensive care unit. J Cardiothorac Vasc Anesth. 2011:25:263-7.

21. Morrison RH, Hall NS, Said M, Rice T, Groff H, Brodine SK, et al. Risk factors associated with complications and mortality in patients with Clostridium difficile infection. Clin Infect Dis. 2011;53:1173-8.

22. Leffler DA, Lamont JT. Clostridium difficile Infection. N Engl J Med. 2015:373:287-8.
23. Bignardi GE. Risk factors for Clostridium difficile infection. J Hosp Infect. 1998:40:1-15.

24. Dubberke ER, Reske KA, Yan Y, Olsen MA, McDonald LC, Fraser VJ. Clostridium difficile--associated disease in a setting of endemicity: identification of novel risk factors. Clin Infect Dis. 2007;45:1543-9.

25. Cho SM, Lee JJ, Yoon HJ. Clinical risk factors for Clostridium difficileassociated diseases. Braz J Infect Dis. 2012;16:256-61.

26. Vreugdenhil H, Heijnen C, Plötz F, Zijlstra J, Jansen N, Haitsma J, et al. Mechanical ventilation of healthy rats suppresses peripheral immune function. Eur Respir J. 2004;23:122-8.

27. Brunson M, Alexander J. Mechanisms of transfusion-induced immunosuppression. Transfusion. 1990;30:651-8.

28. Jennings DL, Chopra A, Chambers R, Morgan JA. Clinical outcomes associated with chronic antimicrobial suppression therapy in patients with continuous-flow left ventricular assist devices. Artif Organs. 2014;38:875-9.

29. Rastan AJ, Tillmann E, Subramanian S, Lehmkuhl L, Funkat AK, Leontyev S, et al. Visceral arterial compromise during intra-aortic balloon counterpulsation therapy. Circulation. 2010;122:S92-9.

30. Vondran M, Rastan AJ, Tillmann E, Seeburger J, Schroter T, Dhein S, et al. Intra-aortic balloon pump malposition reduces visceral artery perfusion in an acute animal model. Artif Organs. 2016;40:334-40.

31. Riddle DJ, Dubberke ER. Clostridium difficile infection in the intensive care unit. Infect Dis Clin N Am. 2009;23:727-43.

32. Carchman EH, Peitzman AB, Simmons RL, Zuckerbraun BS. The role of acute care surgery in the treatment of severe, complicated Clostridium difficile-associated disease. J Trauma Acute Care Surg. 2012;73:789-800.

\section{Ready to submit your research? Choose BMC and benefit from:}

- fast, convenient online submission

- thorough peer review by experienced researchers in your field

- rapid publication on acceptance

- support for research data, including large and complex data types

- gold Open Access which fosters wider collaboration and increased citations

- maximum visibility for your research: over $100 \mathrm{M}$ website views per year

At $\mathrm{BMC}$, research is always in progress.

Learn more biomedcentral.com/submissions 